\title{
Historiografia e significação histórica em Fernando de Azevedo
}

\author{
Marlos Bessa Mendes da Rocha \\ Universidade Federal de Juiz de Fora, Programa de Pós-Graduação em Educação
}

O posicionamento político de inúmeros atores educacionais ante o Estado Novo que tiveram ações e formulações decisivas nas renovações educacionais propostas especialmente durante a primeira metade da década de 1930 é algo que carece de mais estudos historiográficos. Há ali uma síntese de concepções diversas que precisam ser referenciadas em seus enraizamentos na tradição do pensamento social e da educação brasileira e na percepção de como essa tradição lida com o novo contexto político.

Com certeza, tem toda razão a crítica às categorias de tradicional e moderno com as quais Fernando de Azevedo, em A cultura brasileira, pensa a significação dos atores educacionais na primeira metade dos anos de 1930. Trata-se, sem dúvida, de simplificação que não dá conta da complexidade de posicionamentos que ali se expressaram (Carvalho, 2003). Inicialmente, meu enfoque neste trabalho procura situar as diferenças de concepções educacionais de Fernando de Azevedo naqueles dois momentos históricos - o pós-1930 e o Estado Novo - em relação a algumas categorias ali existentes e selecionadas por mim para então entender as razões da mutação, por conta do novo contexto autoritário instalado no país mas também pelos fundamentos teóricos que o autor abraçou. Em seguida, busco analisar o uso das duas categorias, tradicional e moderno, na historiografia de Azevedo, fundada na sua obra maior. Remeto, então, o autor à tradição do pensamento social brasileiro, bem como procuro entender o deslocamento constituído por ele nessa tradição. Fecha-se o texto com uma tentativa de pensar a dissonância em Azevedo ou o paradoxo: a significação de seu pensamento e da sua ação educacional no final da década de 1920 e na primeira metade dos anos de 1930 e o sentido distinto dado por ele na formulação de A cultura brasileira, publicado pela primeira vez em 1943.

Os dois aspectos - o político e o teórico - certamente estão interligados, e a reflexão sobre um deles lançará luz sobre o outro. Meu esforço será desenvolver um exercício comparativo sobre a textualidade de Fernando de Azevedo na referida obra, confrontando-a com formulações suas em textos da primeira metade dos anos de 1930, buscando compreender o que o leva a um entusiasmo sobre a política educacional do Estado Novo que, aos olhos de hoje, nos parece 
despropositado. ${ }^{1}$ Ao longo do texto, pretendo fazer um exercício hermenêutico que explicite o paradoxo do autor, que provocou deslocamentos conceituais e políticos relevantes, no final dos anos de 1920 e primeira metade dos anos de 1930, no pensamento social e educacional brasileiro sem que, no entanto, tenha permanecido fiel à novidade que ele criou no contexto político seguinte. Diga-se que a explicitação desse olhar de Fernando de Azevedo pode ser também fundamentalmente o de tantos outros colaboradores do Estado Novo em matéria educacional, como Lourenço Filho, Teixeira de Freitas, Nóbrega da Cunha e Celso Kelly, entre outros, ativos líderes que foram das posições renovadoras naqueles anos da década de 1930, de intenso debate. ${ }^{2}$ Talvez esta reflexão possa colaborar no esforço de entender a transfiguração sofrida por tantos princípios caros aos renovadores na fase histórica do regime autoritário de 1937.

\section{Alterações da percepção}

O que mudou na percepção de Fernando de Azevedo em A cultura brasileira a respeito de questões de educação defendidas nos primeiros anos da década de 1930 e mantidas mais ou menos incólumes até a Constituição de 1934, pelo menos? Inúmeros aspectos suscitados pelas referências de Azevedo naquela obra podem ser confrontados com as perspectivas vigentes quando do Manifesto dos Pioneiros e outras intervenções do

${ }^{1}$ Trabalhei com base na $3^{\mathrm{a}}$ edição de $A$ cultura brasileira (1958), revista e ampliada. O cotejamento com a edição original (de 1943) revela que a revisão e a ampliação se deram apenas na parte referente ao ensino superior, estendendo-se em considerações que abarcam os primeiros anos da década de 1950.

${ }^{2}$ Uso aqui a designação renovador, já consagrada na historiografia educacional brasileira, para o movimento educacional que agregou importantes educadores na primeira metade da década de 1930, cujo ideário fundamental foi redigido por Fernando de Azevedo no conhecido Manifesto dos Pioneiros (1932), assinado por 26 educadores relevantes àquela época, que mantiveram uma ação coesa na educação pelo menos até o processo constituinte de 1933-1934. autor, como as do V Congresso Brasileiro da Educação, promovido pela Associação Brasileira de Educação (ABE) em Niterói (1932). ${ }^{3}$ Não farei o inventário dessas diferenças, tampouco alargarei o espectro de obras do autor, porque o que interessa é destacar alguns condicionantes, contextuais e conceituais, da evolução do seu pensamento. Três aspectos serão trabalhados: 1) a compreensão do papel da União nos sistemas de ensino; 2) a questão da nacionalização da educação; 3) a visão de ensino profissionalizante.

Quanto ao primeiro aspecto, sabe-se o quanto foi relevante para os renovadores a defesa da participação da União em todas as esferas do ensino, contrariando a tradição advinda do ato adicional de 1834, que relegou o ensino elementar e o ensino profissionalizante para o âmbito provincial. A consciência dessa questão aguçase com o sentido histórico assumido pela Revolução de 1930, em sua dinâmica revolucionária, que traz no bojo a exigência de redefinição do papel da União diante dos estados. No campo da educação, os renovadores assumem com desenvoltura a questão, já a colocando no Manifesto dos Pioneiros em termos de formula-

${ }^{3} \mathrm{O}$ confronto de dois trabalhos da lavra de Azevedo, o Manifesto dos Pioneiros e A cultura brasileira, pode causar estranheza por conta da natureza distinta dessas obras. O primeiro é um manifesto público, assinado por 26 educadores; o outro, uma obra de autoria pessoal. Ora, sabe-se que o Manifesto, a despeito dos seus 26 signatários, é bem a expressão de apenas um deles: o seu redator. De um dos signatários, Anísio Teixeira, sabemos que a sua concordância com os termos do manifesto não é estrita. No entanto, ele foi capaz de, com certeza da mesma forma que os demais, perceber que o documento tinha formulação inovadora, que traria impacto à política pública de educação à época, e que de alguma forma sintetizava pontos de vista que se vinham estruturando no debate político e educacional, pelo menos desde a liderança assumida por Azevedo entre um grupo de educadores do Rio de Janeiro quando da reforma por ele implementada no Distrito Federal (1927-1930). A urgência de lançamento do Manifesto, revelada em cartas pessoais trocadas entre Azevedo e seu amigo Francisco Venâncio Filho, mostram como o documento praticamente não foi debatido no grupo dos signatários (agradeço a Alberto Venâncio Filho o acesso às cartas). 
ção de diretrizes gerais de ensino pela União, bem como do exercício de ação supletiva onde se fizesse necessária, além da estimulação do processo educativo por meio de estudos, inquéritos, demonstrações e subvenções. Não foi em outros termos que se deu o posicionamento desse ator educacional na Constituinte de 1933-1934. Tal posicionamento, entretanto, não o fazia adepto de um controle da União sobre todos os sistemas de ensino. Na emenda 1.845 ao substituto da Comissão Constitucional, naquela constituinte, não há concessão ao centralismo da União, relegando organização, administração e custos dos sistemas públicos à competência dos estados e Distrito Federal. Quanto à fiscalização das diretrizes nacionais, elas seriam da esfera dos conselhos de educação, nacional e estaduais, que contariam com a participação de segmentos da sociedade e de professores.

Ora, já não será nesses termos que Fernando de Azevedo entenderá a questão do papel da União quando a formula em A cultura brasileira. Aqui ele destaca a orientação unitária das duas últimas constituições, de 1934 e 1937, no sentido de romper a tradição republicana da União de abster-se em matéria de política escolar, agora preservando exclusivamente para si a competência "de fixar as bases, determinar os quadros e traçar as diretrizes da educação nacional" ${ }^{4}$ Critica o "federalismo excessivo [...] em que as formações locais, os usos, as resistências e os traços de caráter de cada região se afirmavam ao ponto de fazerem frente ao poder federal, criando um 'imperialismo de campanário’ [...]”. Trata-se agora “de um regime de unidade e de centralização que trouxe consigo a sanção de um poder forte, a abolição das barreiras interiores, a co-penetração dos costumes, das legislações, dos negócios públicos e, particularmente, dos sistemas de cultura e educação". Percebe-se que não se trata de uma simples descrição do que se faz naquele tempo, mas de um posicionamento favorável a tal política.

Outro exemplo de mudança significativa de posicionamento dá-se no que se refere à compreensão da

${ }^{4}$ Todas as citações aqui realizadas encontram-se entre as páginas 188 e 199 da edição mencionada em nota anterior. nacionalização da educação. Nesse aspecto, seguindo coerentemente o entendimento do papel da União, os renovadores compreendem, pela escrita de Azevedo no Manifesto, que a nacionalização da educação se faz via diretrizes gerais formuladas pela União, para todas as esferas de ensino. Porém, "[o] espírito da verdadeira comunidade popular e no cuidado da unidade nacional não implica um centralismo estéril e odioso, ao qual se opõem as condições geográficas do país e a necessidade de adaptação crescente da escola aos interesses e às exigências regionais" (Azevedo et al., 1932).

Esse posicionamento advém do debate cultural inaugurado pela Semana de Arte Moderna de 1922 e revela-se claramente pela valorização do regional, passando a dimensão da brasilidade antes por essa regionalidade, em contraposição a outros pensadores à esquerda e à direita, que buscaram encontrar uma essência brasileira na cultura nacional. No entanto, já não é assim que Azevedo compreende a questão cultural naqueles anos do Estado Novo. A tônica passa a ser a "unificação dos sistemas educativos", a "unidade fundamental de diretrizes", a exigência do novo regime "para realizar uma obra de assimilação e reconstrução nacionais" (sic).

Finalmente, a dissonância que se pode perceber no trato da questão do ensino profissional. A categoria trabalho no Manifesto tem um papel relevante. Ali são duas as dimensões importantes: por um lado, o conceito refere-se à atividade da compreensão humana, como aquisição ativa da cultura; por outro, como ação de formação moral do homem, em que se constituem os laços de cooperação e socialização. Não se trata, portanto, de um trabalho meramente produtivo, pois a tônica recai na dimensão moral que julga a pertinência do processo produtivo. Como nos diz Azevedo no Manifesto: "é preciso fazer homens, antes de fazer instrumentos de produção". ${ }^{5}$ Pode-se mesmo dizer

\footnotetext{
${ }^{5}$ Penso que não se pode encontrar significados da compreen-
} são de Azevedo sobre ensino profissional no Manifesto apelando para formulações do mesmo autor em obras anteriores, como o Inquérito de 1926, senão para perceber o sentido do deslocamento conceitual. Parece-me que nessa última obra Azevedo ainda é 
que Fernando de Azevedo, ao enfocar assim a questão do trabalho, avança em relação à geração cultural da qual fez parte, que Vicente Licínio Cardoso chamou de "nascida com a República". Aqueles dessa geração, que fizeram da educação a principal bandeira de suas ações político-sociais, justificavam-na pela simbiose da dimensão produtiva e da dimensão político-moral: formar o trabalhador nos modernos processos de divisão do trabalho e preparar o indivíduo para ser um eleitor consciente. Azevedo rompe com a simbiose que vem lá do Império, com Tavares Bastos, e destaca a dimensão moral como avaliadora da dimensão produtiva. ${ }^{6}$

Mas já não é assim que a formulação do autor se faz no novo tempo. Azevedo mostra-se um entusiasta da política de ensino técnico e profissional do Estado

portador de uma concepção que acentua escolas-oficinas e escolas de trabalho como lugar de "corrigir pelo manualismo o nosso desamor aos trabalhos corporais" (Azevedo, 1937, p. 5), numa formulação ainda herdeira das concepções de sua geração na qual se acentua a contraposição à cultura verborrágica identificada na tradição brasileira. Já no Manifesto, e mesmo antes, na reforma do Distrito Federal (1927-1930), suas concepções modificam-se e caminham no sentido de juntar a concepção de "escola do trabalho" (Kerschensteiner) e "escola ativa" (Dewey), conforme explicitado por ele na conferência de 21 de novembro de 1929 (Azevedo, s.d., p. 84). Os sentidos dos conceitos precisam ser resgatados no seu próprio tempo de ocorrência, sob pena de misturarem-se injunções de épocas diversas, ainda que temporalmente próximas.

${ }^{6}$ Aureliano Cândido Tavares Bastos em A Província, obra publicada em 1870, no capítulo relativo à instrução pública, justifica a exigência pública de expansão da escolaridade com o duplo argumento de formar o cidadão, inclusive aqueles provenientes do processo emancipatório, e de qualificar a mão-de-obra para o uso de tecnologias do processo produtivo. $\mathrm{O}$ autor é referência para a geração de Azevedo e citado recorrentemente, por exemplo, por Vicente Licínio Cardoso. No que se refere à política pública de educação, Tavares Bastos é estimulador de uma educação pública extensiva, inclusive com a participação da União. É nesse sentido que não pode ser entendido como um liberal econômico tout court, como algumas leituras contemporâneas fazem.
Novo. Chega a dizer que a Constituição de 1937, por esse aspecto, é "a mais democrática e revolucionária das leis que se promulgaram em matéria de educação". Nenhuma palavra a respeito do caráter dualista explícito dessa constituição ao destinar o ensino profissional "às classes menos favorecidas". Ora, esse fora um dos aspectos mais relevantes do Manifesto, que inaugura no pensamento social brasileiro a consciência da injustiça social estruturada nos sistemas de ensino. $\mathrm{O}$ que o autor valoriza no novo acento dado ao ensino profissional é a contraposição a uma tradição beletrista que marcou, desde épocas remotas, o ensino nacional. O entusiasmo de Azevedo dirige-se à nova estruturação do ensino profissional, trazida "pela ligação orgânica da teoria e da prática, assegurada pela aplicação imediata das lições do laboratório, pela organização do trabalho, nos campos e nas oficinas, e pela colaboração obrigatória das indústrias e do Estado na preparação de operários qualificados". Pelo visto, nenhum problema mais o aflige no que diz respeito à pura adequação da formação às exigências produtivas. A prevalência da dimensão moral na formação integral do educando, que foi um relevante atributo daquele Manifesto de sua lavra, ficou esquecida.

\section{Contexto e conceito}

O que pode ter provocado essas mudanças de perspectiva de Fernando de Azevedo, num espaço de menos de 10 anos? Acho que a resposta a tal questão se desdobra em duas dimensões. Uma primeira, de caráter político-contextual, e uma outra que remete mais profundamente às suas concepções teóricas e ideológicas. Com certeza, acontecimentos políticos ocorridos entre nós nos anos de 1935 e 1938, mencionados explicitamente no texto da obra maior, servem de alerta para a compreensão de suas novas formulações.

Como Azevedo os leu? Há em A cultura brasileira algumas poucas referências que podem trazer alguma conotação para seu posicionamento político naqueles anos. Parece-me que o autor compreende os eventos de 1935 (rebeliões populares/militares desse ano: Natal, Recife e Rio de Janeiro), bem como 
o putsch integralista de 1938 ao Palácio Guanabara (Rio de Janeiro), sede do governo da União, como manifestações de uma radicalização política que decorria dos ventos mundiais de uma época totalitária, que era apenas uma das expressões das exigências históricas de redimensionamento do papel do Estado na época contemporânea. ${ }^{7}$ Ante tais circunstâncias históricas, era preciso que o Estado impusesse sua regra de unidade, para evitar a fragmentação nacional, trazida no bojo daquela radicalidade. $\mathrm{O}$ Estado Novo, a despeito de seu caráter autoritário, não é compreendido, entretanto, como totalitário, à semelhança daqueles estados europeus (Alemanha, Itália, União das Repúblicas Socialistas Soviéticas URSS) vistos assim. Algumas passagens me fazem crer nessa hipótese: por exemplo, quando ele exorta a política escolar de caráter nacional proposto pela Constituição de 1934, em continuidade na de 1937, argumenta que ela favorece "no país uma educação bastante livre para respeitar as diversidades, mas bastante forte para fazer progredir a obra comum no respeito dessas diversidades". Mais adiante dirá que a política de unidade nacional, que "esbarrava [...] em resistências locais e particulares [...] acabaria por ser vencida, mais do que pela força, pela doçura e pelo tempo, como pela cooperação inter-administrativa dos estados e da União". Assim, o regime autoritário do Estado Novo faz jus ao seu tempo, na compreensão de Fernando de Azevedo, enfrentando o risco da fragmentação nacional apontada pela radicalização

${ }^{7}$ No texto A cultura brasileira, não é possível encontrar justificativa explícita para a percepção de Azevedo dessa exigência histórica de redimensionamento do papel do Estado na época contemporânea. Nesse aspecto, apelo aqui para a conferência feita

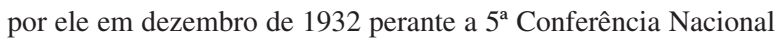
de Educação, realizada em Niterói (Azevedo, 1953, p. 79). Nesse texto, Azevedo explicita sua compreensão de modernidade estatal no tempo contemporâneo, atribuindo o que se passa na Alemanha, Itália e URSS à expressão dessa modernidade pelo alargamento que ali ocorre do papel do Estado na construção social. Esse fundamento teórico parece-me que ainda prevalece quando da formulação daquela obra, em 1943. política, alargando a natureza do Estado necessária aos novos tempos e abarcando as diferenças de um ponto de vista amplo, do interesse geral.

Para além dessa compreensão mais estritamente política e contextual, é preciso que a análise se remeta aos fundamentos teóricos de suas concepções. ${ }^{8} \mathrm{O}$ Estado Novo é, para o autor, o ápice de um movimento democrático que nasce com a Revolução de 1930. A expressão democrática desse regime na educação fez-se tanto na preservação constitucional, em 1937, de certos princípios que foram defendidos pelos $r e$ novadores, como por um movimento de crescimento educacional que ocorreu na sociedade, expandindo especialmente a educação elementar, a educação profissional e a educação secundária. Na educação profissional, louvam-se as novas iniciativas (criação de escolas técnicas federais) empreendidas pelo Estado Novo. Já na educação secundária, percebe-se que tal crescimento é desestabilizador da concepção humanista, propedêutica e dualista, que inspirou a reforma desse segmento, em 1931, com Francisco Campos à frente do Ministério de Educação e Saúde Pública (MESP), reforma mantida pela Constituição de 1934 e pela de 1937. O crescimento do ensino secundário, se não o tornou um “"ensino para o povo', [o tornou] ao menos um ensino de caráter mais democrático". Assim, o caráter político do novo regime não é a expressão apenas de suas propostas políticas, mas também desse movimento democrático, que se impõe a partir da sociedade, às vezes forçando caminhos que vão além das subjetivações que possam querer conduzir o processo histórico.

\footnotetext{
${ }^{8}$ Nosso fundamento historiográfico aqui é o de que o conceito
} não é meramente justificador de um posicionamento ideológico ante o contexto político. O conceito tem uma historicidade própria que não o faz mero reflexo. Tal historicidade se remete a uma tradição da qual o conceito é um registro de continuidade, de mudança ou, mais comumente, das duas dimensões imbricadas. Alguns autores na linha da hermenêutica histórica contemporânea (Hans Gadamer, Paul Ricoeur) justificam essa abordagem. Cito, entretanto, outra linha de argumentação para justificá-la: Quentin Skinner (1996), especialmente no prefácio da obra. 
É bom perceber que nesse tipo de entendimento de Azevedo não existe aquela questão clássica de uma sociologia weberiana, que percebe a mutação dos significados históricos de acontecimentos ao longo do tempo. Trata-se, sim, de um sociologismo que compreende os processos históricos independentemente das subjetivações que se fazem neles. As concepções dualistas de Francisco Campos na implementação da reforma do ensino secundário pouco importam; o que vale é o andamento do processo histórico que efetiva o ensino secundário, cujo resultado é democratizador.

Pode-se buscar a raiz desse naturalismo sociológico no pensamento social que marcou a geração de Azevedo. Mas antes de recorrer a essa tradição, desenvolvida mais adiante, já nos escritos de Azevedo no pós-1930 se encontram indicações precisas sobre o seu fundamento conceitual. Usarei aqui o texto já citado, a conferência de Azevedo no V Congresso da ABE, em 1932. Nessa palestra, o autor propõe-se a responder, de um ponto de vista teórico, a questão da nova dimensão assumida pelo Estado na educação. Para fazê-lo, ele estende-se em considerações teóricas que se iniciam pela definição do que é público e do que é privado. A formulação das duas categorias submete-se à compreensão de John Dewey, citado no texto, que as define por uma empiria: a capacidade de extensão da ação social. É privada a ação que traz conseqüências limitadas ao indivíduo e ao seu entorno; é pública aquela cujo alcance das conseqüências dos atos é "tão importante que necessita ser governado já por inibição, já por promoção" (Azevedo, 1953, p. 74). Ao longo do tempo histórico, o que antes era considerado uma ação privada pode transformar-se em pública. Na própria definição do que é público já se esboçam funções do Estado: inibir ou promover os atos de dimensão pública. Antes de definir Estado, porém, é preciso delimitar o "público", que, levado pela necessidade de organização, se transforma em Estado. "O 'público' se constitui de todos aqueles a quem afetam as consequiências nas transações entre pessoas singulares ou grupos, em tal proporção que se considera necessário cuidar sistematicamente dessas conseqüências" (idem, ibidem).
Parece-me que Azevedo está buscando dar conta de uma definição de público que, ao mesmo tempo em que se fundamenta como recorte ou parte da sociedade, se configura também como dimensão que conduz o todo social. O conceito das ciências sociais contemporânea que me vem à cabeça para dar conta dessas duas dimensões - a de ser expressão de parte da sociedade ao mesmo tempo em que a conduz - é o de hegemonia em Antonio Gramsci. Mas seria Fernando de Azevedo um gramsciano avant la lettre? Creio que não. Até porque para Gramsci a natureza do Estado é um problema. O maior ou menor uso da força, a maior ou menor capacidade de convencimento do conjunto da sociedade qualifica a natureza desse Estado. Há nesse autor uma intermediação entre o puro domínio social e a capacidade de condução da sociedade como um todo que passa pelo projeto político do ator que disputa a hegemonia do todo social.

Azevedo não faz qualquer intermediação entre o social e o Estado. É a natureza do "público" que se faz Estado que determinará a capacidade de impulsionar o progresso, entendido este como impulsão da "mobilidade" e da "heterogeneidade social" (idem, p. 80). As dimensões do "público" e da estrutura social estão intimamente relacionadas. Se a estrutura social é fechada, controlada por determinada classe que se transforma em Estado, aí sim haverá antagonismo entre o "público" e o social (idem, p. 77).

Enfim, o que quero destacar em Azevedo, nessa sua argumentação teórica, é que a ausência de uma problematização da natureza do Estado e, portanto, do regime político e de sua legitimidade - porque ele é pura expressão do social - o conduz conseqüentemente não apenas para a sua flexibilização política ante a aceitação do regime autoritário de 1937, mas também para a desqualificação das estratégias subjetivantes da política, vale dizer, da política como formulação conduzida por referenciais holísticos sobre a sociedade que quer construir.

Mas que consciência teórica é essa, justo de quem foi formulador arguto, nos anos de 1930, de uma estratégia de ação político-educacional que colocou a educação no âmago de um plano de reconstrução da nação? 


\section{O moderno e o tradicional}

Creio que agora se pode revisitar os conceitos de tradicional e de moderno formulados em A cultura brasileira, que balizaram a visão historiográfica de Azevedo sobre os acontecimentos político-educacionais ocorridos na primeira metade dos anos de 1930. Diga-se logo que, a meu ver, não se trata apenas de uma visão de Azevedo a posteriori, crivada pelos marcos ideológicos do regime autoritário que lhe encomendou a obra. Já nos escritos dos anos de 1920, quando da reforma educacional do Distrito Federal empreendida por ele, bem como no próprio Manifesto dos Pioneiros, tais categorias já aparecem. Não creio, portanto, que elas sejam mero jogo de estratégia política para desqualificar o adversário. A categoria de moderno que se formula nessas obras quer qualificar o novo que se está construindo ou formulando. Mas o novo, para Azevedo, não é uma construção arbitrária, fruto de subjetivação doutrinária que toma seus princípios como verdade; ele é produto de uma necessidade. Tal necessidade se impõe sobre a nação como decorrência da complexidade social que ela já adquiriu, trazida pelos novos processos produtivos e tecnológicos, pela diversidade urbana, pelas novas tecnologias de transporte e comunicação. O tradicional, por sua vez, é o que se respalda na sociedade que está em vias de ser suplantada.

A partir dessas categorizações, tradicional e moderno, não há espaço para entender uma formulação nuançada, que combine tais dimensões na qualificação dos atores sociais em disputa. E isso por conta de um pensamento social que se quer "orgânico" a uma sociedade. Isso significa que, para Azevedo, todo pensamento social precisa colar-se a uma realidade não como construção sobre ela, mas como expressão dela, sob pena de ser entendida como subjetividade solta, "arbitrária". Trata-se, portanto, de um pensamento moderno apenas quando ele expressa uma necessidade imanente de auto-revolucionamento da sociedade. Por sua vez, o pensamento tradicional é algo a ser superado, porque é a expressão de uma sociedade em vias de extinção. Da mesma forma que não há espaço para uma autonomia da política como projeto, também não o há para o pensamento. Ele é imanente ao social.

Eis aí uma herança clara da cultura política advinda daquela geração, categorizada por Vicente Licínio. Uma matriz conceitual desse pensamento é Alberto Torres. Não vou aqui me estender sobre a caracterização de tal autor, objeto de minha análise em outro trabalho (Rocha, 2004). Apenas destaco que a idéia de imanência do pensamento à sociedade que o produz teve papel relevante na transição de uma cultura política da "ilustração brasileira" (Barros, 1986), ainda fundada em dimensões doutrinárias, herança das duas últimas décadas do Império e mantida nas primeiras décadas republicanas. Alberto Torres rompe com o doutrinarismo ao enfocar problemas concretos da nação: industrialismo, reforma agrária, meio ambiente etc. Entretanto, essa mesma herança, de imanência social da política e do pensamento, que teve lá o seu lado positivo para o estabelecimento de uma nova ordem do pensar, não abre espaço para a invenção.

Não obstante a influência dessa matriz de pensamento em Azevedo, ele soube ir além dela no contexto dos anos de 1920 e primeira metade dos anos de 1930. Trata-se de um sentido que pode ser percebido na reforma educacional de Fernando de Azevedo implantada no Distrito Federal (1927-1930) que, a meu ver, modifica a idéia de povo ainda predominante naquela geração, qual seja, a de um povo que precisa ser incorporado à nação, porém a quem é imputado o não-protagonismo social. Azevedo rompe com tal pensamento não apenas ao afirmar a capacidade de participação do povo, mas também ao condicionar a realização do projeto político de democratização da educação a essa participação. Para que tal se dê, no sentido almejado, é preciso que se pense na educação como um processo de transcendência das situações e percepções vividas, de forma que se introduza os modernos valores de cooperação, de solidariedade, de socialização, superando o homem egoísta da tradição social a ser suplantada. ${ }^{9}$ Ora, como fazê-lo,

9 Divirjo aqui de outros leitores de Azevedo que vêem nele uma influência estrita de Émile Durkheim. A idéia de educação como 
senão pelo entendimento da política como projeto de nação, portanto, como subjetivação, rompendo com a visão de política em sua versão naturalista, de fazer a coisa certa?

\section{O paradoxo}

Percebo, então, que estamos diante de um paradoxo: o que foi lá atrás, no final da década de 1920, o sentido de uma novidade na compreensão da política, superando os marcos político-culturais advindos dos primeiros tempos modernistas (Alberto Torres), herdados ainda pela geração "nascida com a República", é, no novo tempo, do Estado Novo, o sentido de um regresso à tradição do naturalismo sociológico, que fora superado pelo próprio Azevedo no contexto daquela reforma educacional da década de 1920. Creio que para entender o paradoxo é preciso, inicialmente,

transcendência social do meio cultural e da sociedade como um todo pela introdução dos valores de solidariedade e cooperação revela nele a compreensão de uma função social da educação como não simples reprodução da sociedade. Aliás, Jorge Nagle, em Educação e sociedade na Primeira República, de 2001, soube bem perceber em Azevedo essa dimensão, ao analisar a reforma do Distrito Federal de 1927-1930. Pode-se até dizer que em Durkheim também existe na educação a função social de transcendência. Porém isso se dá, nesse autor, pela formação geral dos indivíduos no processo de construção de suas individualidades morais autônomas, própria da cultura moderna do Ocidente. Em Azevedo, porém, a transcendência faz-se não apenas no campo individual da formação geral, mas como processo coletivo, institucional e cultural. A escola não é passiva ao meio. No entanto, a superação de Durkheim por Azevedo nesse aspecto não significa a não-influência daquele em tantos outros aspectos. Quando Azevedo, no próprio Manifesto, se refere à finalidade da educação acompanhando uma "concepção de vida", variável no tempo e no espaço, decorrente sempre das "estruturas" e "tendências sociais" da época, sem dúvida, a inspiração é tipicamente durkheimiana. Do ponto de vista hermenêutico, entretanto, apontar um deslocamento conceitual num autor não implica necessariamente supor um sujeito inteiramente consciente e coerente com a novidade que constitui. Trata-se de perceber na textualidade uma significação objetivamente dada que ultrapassa as intencionalidades de autoria. tomar consciência de certos fundamentos teóricos que embasam uma nova história das idéias, que já não pode ser fundada numa concepção de sujeitos autoconscientes de sua construção. As idéias são expressão, antes de tudo, de sentidos de existência, o que naturalmente remete para muito além desse cogito pensante.

Esse sentido de existência precisa ser percebido pelo historiador com a objetividade do contexto histórico, o que evidentemente não se reduz aos dados empíricos do contexto. A dimensão subjetiva de um dado contexto é, também ela, uma dimensão objetiva, porque deixa sua marca de existência naquele contexto. Ainda que tal marca não tenha sido suficiente para produzir efeitos históricos imediatos, que assegure o futuro que se segue em contínuo como história vencedora, ela ali deixou traços que poderão ser resgatados no futuro. Quem faz tal resgate são as interpretações que o futuro formulará, sempre nos marcos de possibilidades produzidos pelo evento e pelo campo conceitual que o expressou e provocou. Vale dizer, o exercício hermenêutico da interpretação precisa ater-se ao contexto, percebendo o que ali é herança e quais os sinais da superação, sem imputação crítica advinda de uma consciência contemporânea que, ao olhar o passado com os valores do presente, acaba por absolutizar-se, saindo do campo da história.

Nossos supostos, então, não podem ser coerência nem equívoco. Ambos seriam devedores de um cogito cartesiano: de um lado, pelo centramento no autor em vez do significado de sua obra; de outro, num cogito crítico contemporâneo que não faz a devida intermediação entre presente e passado. A clareza sobre certos fundamentos teóricos de uma nova historiografia das idéias, embora nos ajude, não soluciona o paradoxo presente no pensamento do autor que estamos trabalhando, ao longo de dois momentos relevantes da sua existência.

Retomando o argumento, afirmo que Fernando de Azevedo teve papel revolucionário na educação brasileira quando da reforma educacional do Distrito Federal, bem como nos anos seguintes daquela primeira metade dos anos de 1930, pelas formulações e implementações em educação que fez ali. As ambi- 
güidades do campo conceitual que o marcou já nesse tempo, no entanto, não permitiram que ele, ante o contexto seguinte (o Estado Novo), problematizasse a natureza do Estado, do regime e de sua legitimidade. $\mathrm{O}$ retorno a um naturalismo sociológico, herança de uma geração, que parecia superado, continuou a marcá-lo e o fez enxergar o Estado Novo como uma possibilidade de realização democrática, por conta do que ele percebia como avanços nos processos de acesso à educação, exaltando a dimensão de maior igualdade na nova ordem social. Uma hermenêutica contemporânea pode avaliar os limites de tal formulação, porém sem imputação de valores julgadores do passado. Seu papel é perceber os traços herdados e como estes convivem na apreensão do contexto histórico.

O paradoxal em Azevedo é que ele é o algoz de aspecto importante da herança num contexto anterior, qual seja o suposto do naturalismo político, que impede o protagonismo do povo na construção do projeto democrático nacional. Como já disse, Azevedo o contraria quando formula a exigência da integração escolar na comunidade e expressa tal exigência como condição para sua democratização. Para que assim o fizesse, precisou enxergar a escola como instituição que transcende o meio social em que se insere. A escolaridade moderna e democrática exige a construção política pautada pelos valores da igualdade, da solidariedade, da cooperação. Trata-se, portanto, de um projeto político que requer a formação de atores políticos que o encaminhem. Professores e comunidade escolar são partes cruciais do elenco dessa construção. Logo, não se trata de um naturalismo sociológico, porque tal construção passa pela formulação de um projeto político. Poderíamos dizer que esse é o lado contemporâneo da formulação de Azevedo. Mas quais são os fundamentos da cultura política de Azevedo?

Antes de qualquer outro considerando, é preciso retomar o registro dessa geração na qual se insere Azevedo: os nascidos com a República. Seu traço político fundamental é seu oposicionismo não a este ou aquele governo, mas a uma prática política sustentada nas maquinações do poder. É o modelo de articulação do poder criado por Campos Salles e que se estende aos demais governos da República Velha, que precisa ser contrastado. Passam a ter importância, então, os problemas reais da sociedade, quais sejam os temas da industrialização, da agricultura, do êxodo rural para o meio urbano, da educação do povo etc. Como já disse, a influência de Alberto Torres é explícita, fazendo-se referência em diversos pensadores dessa geração. Azevedo mesmo cita-o no Manifesto dos Pioneiros por mais de uma vez. Não é difícil, assim, imaginar o porquê dos ares hegelianos nos conceitos de Azevedo. Trata-se de uma mudança de tônica no fazer político: do poder do Estado para o poder da sociedade. Nesse aspecto, a geração de Azevedo aponta para um deslocamento conceitual e político.

Outro registro que também marca a geração de Azevedo refere-se ao que já mencionei como compreensão naturalista da política. Diga-se que esse registro vem mais lá de trás, da geração antecessora, que Roque Spencer de Barros chamou de "ilustração brasileira". Ela compreende a política como o fazer a coisa certa. Requer uma elite governativa esclarecida que saiba o que deve ser feito para atender às necessidades da nação e do seu povo. Ao refletir sobre o registro anterior, o oposicionismo fundamental ao modelo político que predominou na República Velha, percebe-se o porquê da manutenção desse último traço na geração sucessora: a desmoralização da prática negociadora intra-elites, que resultava na perda da dimensão pública, pois não escondia os atos de força que dali provinham. A conclusão parece óbvia: a negociação das partes interessadas na política não é o caminho da boa política, ou seja, o que deve interessar ao povo e à nação brasileira. Assim, suprime-se a negociação (a política) e coloca-se em seu lugar a clarividência das elites governantes. Alberto Torres é bem a expressão dessa clarividência na medida em que, para ele, compete às elites esclarecidas, sintonizadas com os "verdadeiros problemas nacionais", a condução da boa política.

Ocorre que tal geração é marcada ainda por outro registro que também provém da antecessora. Trata-se da influência de Euclides da Cunha. Muitos 
da época de Azevedo se dizem euclidianos; alguns, inclusive, como Francisco Venâncio Filho, amigo íntimo, é freqüentador do Clube Euclides da Cunha, que se reunia anualmente na cidade de São José do Rio Pardo. Não preciso dizer que a história que aqui se busca tecer não trata das idéias como influência na forma da antiga historiografia das idéias. A questão é: o que na obra magna de Euclides, Os sertões, é tão decisivo que marca a geração seguinte? Euclides da Cunha, em muitos traços que o caracterizam, é um homem da "ilustração brasileira": seus argumentos são teórico-doutrinários, sua formulação é centrada na preocupação literária - como destacou Walnice Galvão (2001). O que não foi ainda suficientemente destacado na nossa historiografia das idéias, entretanto, é o papel de inflexão que Euclides exerce nesse paradigma da "ilustração".

Saliento, então, uma dimensão moderna de Euclides que influenciou a época seguinte, bem expresso por Vicente Licínio Cardoso, que também se dizia euclidiano. Trata-se ali do conceito de desenvolvimento formulado por Euclides em À margem da história (Cunha, 1967), que aponta para uma dimensão substantiva do fazer político; não o compreendendo como simples recurso de poder, já aí antecedendo a sintonia com o futuro. Para além desse marco conceitual, entretanto, há ainda em Euclides outra contribuição ao pensamento social brasileiro que o torna decisivamente precursor da nova geração. Euclides construiu uma obra que se contrapôs a um suposto fundamental que marca o pensamento social de sua época: a compreensão abstrata de povo, qualquer povo, que impede de percebê-lo como protagonista da construção nacional. Somente as luzes da razão civilizatória seriam capazes de construir a nação. ${ }^{10} \mathrm{O}$ recado de Euclides é de que,

${ }^{10}$ Trata-se de uma formulação complexa que não poderíamos desenvolver neste espaço. Apenas assinalo que, em nossa hipótese interpretativa do pensamento social brasileiro, há descontinuidade entre a cultura política do Império e a da República. A primeira conviveu durante décadas com a participação eleitoral de um “demos", na definição de Renato Lessa (Lessa, 1988), majoritariamente analfabeto. As reformas políticas que empreendeu, desde para além de uma cultura formal civilizada, tão ao gosto dos seus pares, exatamente no contrapé dessa cultura, como cultura do litoral aberta às influências estrangeiras espúrias, pois retiram a nossa autenticidade, está uma dimensão verdadeiramente autêntica do nosso povo, étnica e culturalmente capaz de valores nobres. Eis aí o traço de uma superação. ${ }^{11}$

o Marquês do Paraná (1855), se voltavam para a busca de maior legitimidade do voto. A última reforma eleitoral do Império (1881) excluiu os analfabetos, porém ainda com o argumento da busca por maior legitimidade do voto. Não foi com esse argumento que a República manteve a exclusão. Para os constituintes de 1891, os analfabetos eram isentos das luzes da cultura civilizatória, portanto incapazes para a participação eleitoral (Cury, 2001). Tratou-se de argumento novo, ausente na cultura política do Império. A geração seguinte aos que fizeram a República respondeu à questão da participação popular na política de duas formas: os herdeiros de Euclides da Cunha, que buscaram a incorporação, acreditando nos valores nobres do povo, pela da via da educação e da tutela moral (o acento neste ou naquele aspecto marca diferença entre os projetos políticos dos atores laicos e católicos, ambos com afinidades euclidianas; Jackson de Figueiredo, líder católico, se dizia euclidiano), e os que caminharam pela resposta de Oliveira Vianna, que justificou histórica e sociologicamente a insuficiência cívica do povo brasileiro à luz da matriz européia, cujo projeto de incorporação fazia-se via Estado.

11 O contraponto de Euclides da Cunha ao abstracionismo cívico é uma dimensão que reputo como inflexão do pensamento social brasileiro. Pode-se pensar os primórdios desse suposto na fase cultural chamada por Roque Spencer de Barros de "ilustração brasileira" (a partir de 1870). Essa guinada de Euclides, que tanta admiração causou no seu tempo e na geração seguinte, vem no bojo da sua preocupação com a fundação de uma perspectiva nacional que remeta o olhar para o interior do país, de seu povo, de sua geografia. Tal entendimento do autor não está ausente numa bibliografia contemporânea sobre o autor, como o trabalho de Regina Abreu (1998). É preciso assinalar, entretanto, que esse entendimento está na contramão de um outro olhar sobre o autor, como o expresso por Luiz Costa Lima (1997). Para esse autor, não é possível separar o argumento de Euclides da construção teórica que o pauta. E essa construção teórica é fundamentada num mito, o da "rocha viva". Valorizar o argumento de Euclides independentemente 
Em importantes aspectos, Euclides e Alberto Torres podem ser considerados inflexão do velho paradigma da "ilustração brasileira", a partir dali criando bases para a constituição de um novo pensamento sobre o Brasil. A grande contribuição foi terem sintonizado com questões da sociedade, em vez de com o poder do governante.

A nova geração de Azevedo é herdeira dessas duas referências: Euclides da Cunha e Alberto Torres. Não obstante, não são herdeiros submissos: eles, antropofagicamente - como diria Mário de Andrade-, digerem esses pensadores e os incorporam à sua maneira. A melhor expressão dessa digestão de influências talvez se encontre no uso que alguns dos seus membros fazem da metáfora do escritor francês Ernest Renan: a do "diamante bruto". ${ }^{12}$ Ela

de seus conceitos, como o fez especialmente a recepção do autor na geração seguinte, seria na verdade incorrer num "substancialismo primário", que antecederia, como idéia, a própria linguagem. Sem dúvida, o debate sobre a questão é teoricamente complexo e merece um aprofundamento que não cabe neste espaço. Ocorre-me, entretanto, a seguinte hipótese interpretativa para enfrentar a questão de Luiz Costa Lima: buscar a significação de um argumento tem a ver naturalmente com os conceitos desse argumento, e a leitura hermenêutica assim nos aponta. Não obstante, essa significação é maior que o conceito; ela expressa um posicionamento existencial no mundo. As palavras são a expressão do argumento e não há idéia que possa anteceder sua expressão lingüística. Porém, a inteligibilidade não é dada por um jogo lógico conduzido por uma epistemologia contemporânea. O sentido das palavras na construção do argumento negocia com uma semântica proveniente da tradição. Portanto, a busca do sentido é regressiva, e não prospectiva. $\mathrm{O}$ olhar contemporâneo é, antes de tudo, de descoberta de possibilidades de sentidos que estavam embutidos no passado. E o resgate do passado faz-se nos princípios e nas práticas. Daí a exigência do resgate dos “contextos ideológicos adequados”, no dizer de Quentin Skinner, já citado, em sua contraposição aos métodos tradicionais "textualistas" na história da idéias políticas.

12 Paulo Ottoni de Castro Maya inicia a apresentação de sua tese, intitulada Educação política, no I Congresso Brasileiro de Educação, promovido pela ABE em Curitiba em 1926, com a citação de Renan sobre tal metáfora. quer expressar o valor intrínseco que estaria dado às dimensões da cultura do povo. Entretanto, tal valor intrínseco, para brilhar, precisaria ser burilado, à semelhança do lapidador que faz brilhar a pedra bruta. Quem faz brilhar a pedra bruta da cultura do povo? Uma elite esclarecida, letrada, que educa o povo. Bem, já não é uma elite governante, como pensava Alberto Torres, que conduz à boa política. A boa política far-se-á a longo prazo, jamais por golpes de força, mas pela formação educacional do povo.

Não façamos aqui a crítica fácil de um cogito contemporâneo que dirá que aí estaria clara uma ideologia autoritária, elitista e conservadora. O que importa destacar é o deslocamento que ocorre. O povo torna-se ator político da boa política, ainda que conduzido. São seus interesses que importam e eles serão descobertos por ele mesmo, bastando que se o prepare para tal descoberta.

Neste ponto, retorno a Fernando de Azevedo. É precisamente no entendimento do povo como ator político no processo de democratização da educação, formulado por Azevedo na reforma do Distrito Federal, que ele se torna um novo ponto de inflexão, agora dentro da sua própria geração. Diferentemente dela, Azevedo não antecede a educação ao processo participativo do povo nem a compreende como intermediada por mentes esclarecidas. A educação do povo dar-se-á num processo institucional, em que a escola é o fulcro do aprendizado e da superação cultural. Essa é a dimensão moderna, diria mesmo contemporânea, do pensamento de Azevedo. Não se trata mais de um burilar da cultura para que ela venha expressar o seu esplendor; trata-se da transcendência de uma cultura local restrita às condicionalidades de uma ambientação fechada e limitada, para que venha a expressar o ambiente do mundo moderno. A escola, estendida às massas populares, teria aí o seu papel. A organicidade pretendida é essa sintonia com as circunstâncias da modernidade do mundo, como algo dado, apontado pelas nações mais avançadas do Ocidente.

Dois atores são fundamentais para a democratização do ensino: os profissionais do ensino e a comunidade escolar, formada pelos segmentos sociais 
presentes no meio social em que a escola se insere. Reforço: esse pensamento de Azevedo não é apenas moderno, é também contemporâneo. Certamente estou na contramão de outras interpretações que tomam a expressão do conceito de "orgânico", expresso por Azevedo, como sinal de concepção autoritária da política, qualificada de "ideologia de Estado", em contraposição ao pensamento político moderno e contemporâneo que seria contratualista, ou seja, pautado pelos critérios liberais clássicos do modelo de mercado. ${ }^{13} \mathrm{O}$ bom acordo da política passaria pelo contrato ou pelo consenso das partes segmentadas da sociedade, e só o poder do Estado poderia fazêlo (Locke). Certamente essa é uma concepção que jamais poderia ter predominado àquele tempo, pois a percepção dominante dessa geração de Azevedo, decepcionada com a República que se tinha, era de esgotamento da pactuação intra-elites, que conduzia o destino da República Velha.

Certamente Fernando de Azevedo não é a expressão desse contratualismo. Isso, entretanto, não faz dele um reacionário autoritário em política, como querem aquelas interpretações. Sua expressão moderna é outra, apontando para uma vertente contemporânea de entendimento da política: a teoria dos atores. $\mathrm{O}$ ator não é a expressão direta de interesses segmentados, até porque o interesse do segmento social não é algo dado naturalmente, mas um processo de construção social. O ator social situa-se no plano da política, ou seja, no plano holístico do arranjo social. Ele precisa fazer com que seus interesses mais específicos não apenas se justifiquem nesse plano do interesse social geral. Isso importa não apenas em generalizações de interesses, mas também em autotransformação ou transcendência das contingências particulares para colocarem-se afinados com o interesse geral. Assim o ator social se constrói.

Azevedo, com toda certeza, não é a expressão refinada de uma teoria política contemporânea, porém aponta no sentido dela. E suas convicções não-contra-

13 Ver a respeito desse tipo de interpretação Lamounier (1977); e, para uma crítica dessa interpretação, Santos (1978). tualistas não poderiam ser muito diferentes no contexto histórico de sua geração, como se viu. Entretanto, a questão que ainda fica pendente de explicação é o porquê de tal concepção de política não se manter no contexto histórico seguinte, o do Estado Novo. Por que Azevedo retrocede a uma visão estrita do Estado, como o realizador do interesse geral, na versão mais autoritária do contratualismo (Hobbes), em que se separa liberdade moral e ordem política? ${ }^{14}$

Inverto aqui a demonstração: do conceito ao contexto histórico. Como foi visto, o conceito de Estado formulado por Azevedo - qual seja, o "público" que se faz Estado - na leitura de Dewey, que define "público" pelo grau de extensão da ação social, sem dúvida, traz dificuldade para combinar-se com a moderna teoria do ator social. Seria talvez preciso fazer outra leitura da teoria hegeliana para melhor adequar a noção de Estado àquela teoria, situando a formação do "público" ainda na esfera da sociedade civil; logo, da construção política. Ao não proceder assim, a relação direta estabelecida por Azevedo entre o "público" e o Estado favorece conceitualmente o retorno a um sociologismo; portanto, à desqualificação da política como projeto.

Para além dessa dimensão conceitual, parece-me que três circunstâncias históricas, por sua vez, são também facilitadoras do "esquecimento" daquela inflexão fundamental que Fernando de Azevedo constituiu em anos anteriores. São elas: 1) antes de tudo, a afirmação no contexto político de um governo autoritário que suprimiu os atores políticos do âmbito mais livre da sociedade civil, incorporando-os seletivamente nos estamentos governativos; 2) o enfrentamento, pelas políticas do Estado Novo, de alguns problemas da nação que, de alguma forma, fizeram parte do acervo de questões que constituíram o debate da modernidade nacional. Ainda que se possa pensar na transfiguração de certos temas e questões pela óptica do regime autoritário, o maniqueísmo na avaliação das políticas que

${ }^{14}$ A respeito da separação, em Hobbes, da moral e da ordem política, ler Reinhart Koselleck (1999), especialmente as páginas 40 a 47. 
se efetivaram ali não é bom conselheiro; 3) as experiências políticas vividas em diversos países relevantes, não apenas naqueles percebidos como totalitários (Alemanha, Itália, URSS), mas também a experiência no coração do mais pujante capitalismo - o New Deal norte-americano -, trazem a percepção de que o papel do Estado se redefine no mundo. Diga-se que essa percepção, advinda do exterior, se combina com as novas expectativas de reforma do Estado trazidas pela Revolução de 1930. Nesse ambiente, tende-se a destacar as continuidades entre 1930 e 1937 e obnubilar as rupturas.

Somente o resgate da política como projeto poderia levantar os critérios de liberdade para a avaliação do regime. E isso não é fruto da crítica de um cogito contemporâneo que olha o passado com os valores do presente. Trata-se da percepção das tendências políticas que se expressavam naquele tempo. Azevedo enxergou no Estado Novo a realização democrática, por conta do que ele percebia como avanços nos processos de acesso à educação em vários níveis, exaltando a dimensão de maior igualdade na nova ordem social, ainda que em detrimento de valores de liberdade. Entretanto, outros educadores renovadores, sobretudo Anísio Teixeira, não abriram mão de avaliar o regime pela óptica de uma democracia que quer avanços na igualdade, porém sem abrir mão de um projeto de nação que não abdica dos valores da liberdade.

\section{Referências bibliográficas}

ABREU, Regina. O enigma de Os Sertões. Rio de Janeiro: Funarte/ Rocco, 1998.

AZEVEDO, Fernando de et al. A reconstrução educacional no Brasil. Ao povo e ao governo. Manifesto dos pioneiros da educação nova. São Paulo: Editora Nacional, 1932.

. A educação pública em São Paulo. Problemas e discussões (Inquérito para o estado de São Paulo em 1926). São Paulo: Editora Nacional, 1937.

A educação e seus problemas. 3. ed. São Paulo: Melhoramentos, 1953.

. A cultura brasileira. Introdução ao estudo da cultura no Brasil. 3. ed. São Paulo: Melhoramentos, 1958.
. Novos caminhos e novos fins. 3. ed. São Paulo: Me-

lhoramentos, s.d. (Obras Completas, vol. VII.)

BARROS, Roque Spencer Maciel de. A ilustração brasileira e a idéia de universidade. São Paulo: EDUSP/Convívio, 1986.

CARVALHO, Marta Maria Chagas de. O território do consenso e a demarcação do perigo: política e memória do debate educacional dos anos 30. In: . A escola e a República e outros ensaios. Bragança Paulista: EDUSF, 2003. p. 329-353.

CUNHA, Euclides da. À margem da história. Porto: Lello Brasileira, 1967.

CURY, Carlos Roberto Jamil. Cidadania republicana e educação. Governo provisório do Mal. Deodoro e congresso constituinte de 1890-1891. Rio de Janeiro: DP\&A, 2001.

GALVÃO, Walnice. Entrevista: "Há uma outra história de Canudos". Jornal do Brasil, 19 maio 2001.

KOSELLECK, Reinhart. Crítica e crise: uma contribuição à patogênese do mundo burguês. Rio de Janeiro: EDUERJ/Contraponto, 1999.

LESSA, Renato. A invenção republicana. Campos Sales, as bases e a decadência da Primeira República brasileira. São Paulo: Vértice; Rio de Janeiro: IUPERJ, 1988.

LAMOUNIER, Bolívar. Formação do pensamento político autoritário na Primeira República. Uma interpretação. In: FAUSTO, Boris (Org.). História geral da civilização brasileira. Tomo III, v. 2. Rio de Janeiro/São Paulo: Difel, 1977. p. 343-374.

LIMA, Luiz Costa. Terra ignota: a construção de Os Sertões. Rio de Janeiro: Civilização Brasileira, 1997.

NAGLE, Jorge. Educação e sociedade na Primeira República. São Paulo: EPU/EDUSP, 2001. (1. ed. 1974.)

ROCHA, Marlos Bessa Mendes da. Matrizes da modernidade republicana. Cultura política e pensamento educacional no Brasil. Brasília: Plano; Campinas: Autores Associados, 2004.

SANTOS, Wanderley Guilherme. Ordem burguesa e liberalismo político. São Paulo: Duas Cidades, 1978.

SKINNER, Quentin. As fundações do pensamento político moderno. São Paulo: Companhia das Letras, 1996.

MARLOS BESSA MENDES DA ROCHA, doutor em educação pela Universidade de São Paulo (USP), é professor da Faculdade de Educação e do Programa de Pós-Graduação em Educação da Universidade Federal de Juiz de Fora (UFJF). Publicações recentes: Educação conformada: a política pública de educação no Brasil 1930-1945 (Juiz de Fora: Editora da UFJF, 2000. Com financiamen- 
to do programa COMIND/INEP/MEC); Matrizes da modernidade republicana: cultura política e pensamento educacional no Brasil (Brasília: Plano; Campinas: Autores Associados, 2004). Pesquisa em andamento: "Políticas de educação, escolarização e estratégias de nação: a transição Império/República”, com financiamento da
Fundação de Apoio à Pesquisa do Estado de Minas Gerais (FAPEMIG).E-mail: marlosbessa@ superig.com.br

Recebido em outubro de 2007 Aprovado em janeiro de 2008 
Marlos Bessa Mendes da Rocha

Historiografia e significação histórica em Fernando de Azevedo

Buscou-se investigar as razões his-

tóricas relativas aos eventos e aos

conceitos que levaram Fernando de 
Azevedo, em sua obra A cultura brasileira, a posicionar-se em defesa das reformas educacionais implementadas pelo Estado Novo, em grande medida em contraposição a formulações defendidas na primeira metade dos anos de 1930, especialmente no Manifesto dos Pioneiros. Num segundo momento, procurou-se entender o porquê do paradoxo entre esses dois momentos. $\mathrm{O}$ método, inicialmente, foi desenvolver um exercício de hermenêutica sobre a textualidade do autor naquela obra, querendo compreender o que o leva a um entusiasmo com aquelas reformas que, aos olhos de hoje, nos parece despropositado. Para estabelecer o confronto entre pontos de vista do próprio autor, trabalhou-se sobre três aspectos: 1) o papel da União nos sistemas de ensino; 2) a questão da nacionalização da educação; 3 ) a visão de ensino profissional.

Palavras-chave: moderno e tradicional; sentido de existência; historiografia das idéias

\section{Historiography and historical} significance in Fernando de Azevedo We seek to investigate the historical reasons, related to events and concepts, which made Fernando de Azevedo, in his work A cultura brasileira, defend strongly the educational reforms implemented by the New State Regime, largely contradicting those views held in the first half of 1930's, particularly in "Manifesto dos Pioneiros" (The Pioneers' Manifesto). Secondly, our purpose is to understand this paradox. The method initially involves an exercise of hermeneutics on the author's textuality in the work in question, seeking to understand what raised his enthusiasm for such reforms, which, from today's viewpoint, seem unreasonable. In order to compare the author's points of view, we focus on three aspects: 1) the role played by the State in the educational systems; 2) the issue of the nationalization of education; 3) the views on professional education.

Key words: modern and traditional; sense of existence; historiography of ideas

\section{Historiografía y significación} histórica en Fernando de Azevedo

Buscamos investigar las razones

históricas en relación a los acontecimientos y a los conceptos que llevaron a Fernando de Azevedo, en su obra A cultura brasileira, a posicionarse en defensa de las reformas educacionales implementadas por el Estado Nuevo, en grande medida en contraposición a formulaciones defendidas en la primera mitad de los años de 1930, especialmente en el Manifiesto dos Pioneros. En un segundo momento, quisimos entender el porqué de la paradoja entre esos dos momentos. El método, inicialmente, fue desarrollar un ejercicio de hermenéutica sobre la composición del autor en aquella obra, queriendo comprender lo que lo lleva a un entusiasmo con aquellas reformas que, hoy a nuestros ojos, nos parece despropositado. Para establecer un confronto entre los puntos de vista del propio autor, trabajamos sobre tres aspectos: el papel de la Unión en los sistemas de enseñanza; la cuestión de la nacionalización de la educación; y la visión de la enseñanza profesional.

Palabras clave: moderno y tradicional; sentido de existencia; historiografía de las ideas 